\title{
Supply Chain Management Ubi Kayu (Manihot esculenta) di Agroindustri Tiwul Instan Kabupaten Gunungkidul
}

\author{
Maysaroh $^{1 *}$, Heru Irianto ${ }^{2}$, Raden Kunto $\mathrm{Adi}^{3}$ \\ ${ }^{1}$ Program Studi Agribisnis Universitas Sebelas Maret, Jl. Ir. Sutami 36 A, Surakarta, Indonesia \\ ${ }^{2}$ Program Studi Agribisnis Universitas Sebelas Maret, Jl. Ir. Sutami 36 A, Surakarta, Indonesia \\ ${ }^{3}$ Program Studi Agribisnis Universitas Sebelas Maret, Jl. Ir. Sutami 36 A, Surakarta, Indonesia \\ Email korespondensi: maysarohmaysaroh@gmail.com
}

\begin{abstract}
This research aims to know: supply chain management; supply chain management model; and supply chain performance of cassava in tiwul instan agroindustry, Gunungkidul Regency. This research is a descriptive study. The location of the research is determine by purposive method. Data analysis method is descriptive using Food Supply Chain Network approach (Vorst) while the supply chain performance is measured by marketing margin and farmer's share calculation. The result of this research shows that supply chain of cassava in tiwul instan agroindustry choose the domestic market as the target market while the development target of this supply chain is improvement in technology, coordination and collaboration, and the procurenment of formal contract agreement among the chain members. Cooperation is conducted by the basic of oral contract among the chain members, the transcation system is done in cash, and there has been government support such as capital aid, equipment, and training of human resource development. The management model of supply chain consist of farmer, collectors, market traders, and tiwul instan agroindustry as the chain members whom performing different activities depending on the input and the output. The most efficient channels is SC4 (farmer (gaplek) $\rightarrow$ market trader (gaplek) $\rightarrow$ tiwul instan agroindustry). SC4 is efficient because it has a relatively low marketing margin, relatively high farmer's share and higher benefit and cost ratio than other channels.
\end{abstract}

Keywords: FSCN, supply chain management, supply chain performance, tiwul instan agroindustry, vorst

\section{INTISARI}

Penelitian ini bertujuan untuk mengetahui: mekanisme manajemen rantai pasok; model manajemen rantai pasok; dan kinerja rantai pasok ubi kayu di Agroindustri Tiwul Instan Kabupaten Gunungkidul. Metode penelitian adalah dekriptif. Lokasi penelitian ditentukan secara sengaja. Metode analisis data merupakan metode deskripif dengan pendekatan kerangka Food Supply Chain Network menurut Vorst dan pengukuran kinerja dilakukan melalui perhitungan margin pemasaran dan farmer's share. Hasil penelitian menunjukkan bahwa sasaran pasar adalah domestik sedangkan sasaran pengembangan berupa peningkatan teknologi, peningkatan koordinasi dan kolaborasi, serta pengadaan kontrak perjanjian formal. Kerjasama dilakukan atas dasar kontrak lisan antar anggota, sistem transaksi dilakukan secara tunai dan terdapat dukungan pemerintah berupa modal, peralatan, dan pelatihan pengembangan sumberdaya manusia. Model manajemen rantai pasok terdiri atas petani, pengepul, pedagang pasar, dan agroindustri tiwul instan sebagai pelaku rantai yang masing-masing melakukan aktivitas berbeda bergantung pada input yang dimiliki dan output yang dihasilkan. Saluran yang paling efisien adalah SC4 (Petani (gaplek) $\rightarrow$ pedagang pasar (gaplek) $\rightarrow$ agroindustri tiwul instan). Saluran tersebut dinilai efisien karena memiliki nilai margin pemasaran relatif rendah, farmer's share yang relatif tinggi serta rasio keuntungan dan biaya yang lebih tinggi dibandingkan saluran lain.

Kata kunci: agroindustri tiwul instan, FSCN, kinerja rantai pasok, supply chain management, Vorst

\section{PENDAHULUAN}

Tiwul adalah hasil olahan dari tepung ubi kayu yang ditambahkan air hingga basah dan dibentuk butiran seukuran biji kacang hijau untuk dikukus dan dikonsumsi. Menurut Kamilah dan Lucia (2015), tiwul dikonsumsi masyarakat dalam bentuk yang dikukus, diberi sedikit garam kemudian disajikan dengan taburan kelapa parut. Tiwul merupakan salah satu makanan khas oleh-oleh dari Gunungkidul, Yogyakarta. Inovasi tiwul instan muncul sebagai upaya memperluas eksistensi serta memperpanjang daya 
tahan produk. Perkembangan sektor pariwisata dan peningkatan jumlah wisatawan mempengaruhi jumlah permintaan tiwul instan terutama pada masa high season yaitu pada masa lebaran dan libur tahun baru. Hal tersebut seperti yang terjadi pada salah satu produsen yang mengalami peningkatan permintaan hingga mencapai $50 \%$ (Atmasari 2015).

Peningkatan permintaan tiwul instan mendorong peningkatan produksi tiwul instan untuk mencukupi permintaan konsumen. Produksi tiwul instan di Kabupaten Gunungkidul sekitar 33,48 ton setiap tahunnya. Peningkatan produksi mengakibatkan kebutuhan singkong atau ubi kayu sebagai bahan baku pun bertambah. Sementara produksi ubi kayu atau singkong di Gunungkidul setiap tahunnya cenderung fluktuatif, seperti yang terdapat pada tabel 1 .

Tabel 1. Luas Panen, Produksi, dan Rata-Rata Produksi Ubi Kayu di Kab. Gunungkidul

\begin{tabular}{ccccc}
\hline No & Tahun & Luas Panen (Ha) & Produksi (Ton) & Rata-rata Produksi (Kw/Ha) \\
\hline 1 & 2010 & 55.679 & $994.271,27$ & 178,57 \\
2 & 2011 & 56.040 & $762.554,00$ & 136,07 \\
3 & 2012 & 55.865 & $772.005,69$ & 138,19 \\
4 & 2013 & 55.231 & $933.414,33$ & 169,00 \\
5 & 2014 & 54.485 & $844.773,26$ & 155,05 \\
6 & 2015 & 50.415 & $781.609,00$ & 155,04 \\
7 & 2016 & 48.244 & $1.029 .196,00$ & 213,33 \\
\hline
\end{tabular}

\section{Sumber: Dinas Pertanian DIY (2017)}

Produksi ubi kayu yang fluktuatif dapat mempengaruhi jumlah produksi tiwul instan. Berdasarkan Disperindag Kabupaten Gunungkidul (2015), diketahui bahwa terdapat 896 unit industri pengolahan ubi kayu yang tersebar di 18 kecamatan di Kabupaten Gunungkidul. Jumlah industri pengolahan ubi kayu yang banyak menunjukkan kebutuhan ubi kayu sebagai bahan baku yang banyak pula. Struktur yang tidak tertata dan koordinasi antar pelaku rantai pasok yang kurang baik mengakibatkan terganggunya pasokan ubi kayu di agroindustri tiwul instan baik dari segi kualitas maupun kuantitasnya. Kurang baiknya aliran informasi antar pelaku rantai pasok mengakibatkan ketidaksesuaian produk yang diminta dengan yang disediakan.

Pihak agroindustri seringkali kesulitan untuk mendapatkan pasokan bahan baku yang sesuai yaitu putih, bersih, kering sempurna dan tidak berbau. Kesulitan mendapatkan produk ini terjadi karena ketersediaan produk yang sedikit dan jumlah pemasok yang terbatas. Hal ini disebabkan karena tidak semua petani mampu menghasilkannya akibat proses pengolahan yang lebih rumit. Keadaan ini berkaitan dengan rantai pasok yang ada. Supply chain management adalah pengelolaan berbagai kegiatan dalam rangka memperoleh bahan mentah, dilanjutkan kegiatan transformasi sehingga menjadi produk dalam proses, kemudian menjadi produk jadi dan diteruskan dengan pengiriman kepada konsumen melalui sistem distribusi (Indrajit dan Djokopranoto 2002). Manajemen rantai pasok (supply chain management) dapat membantu dalam mengontrol ketersediaan ubi kayu dan dapat membantu dalam mengetahui peran masing-masing pelaku rantai pasok sehingga dapat dilakukan perbaikan koordinasi dalam menyalurkan produk dari petani ubi kayu hingga agroindustri tiwul instan. Selain itu analisis kinerja dapat dijadikan acuan perbaikan rantai pasok yang ada. Hal tersebut yang melatarbelakangi penulis melakukan penelitian dengan tujuan untuk: Mengetahui mekanisme manajemen rantai pasok, model 
manajemen rantai pasok, dan kinerja rantai pasok ubi kayu di Agroindustri Tiwul Instan Kabupaten Gunungkidul.

\section{METODE PENELITIAN}

Metode dasar penelitian ini yaitu deskriptif. Penentuan lokasi penelitian dilakukan dengan sengaja (purpossive). Kabupaten Gunungkidul dipilih dengan pertimbangan terdapat agroindustri tiwul instan yang berproduksi secara kontinyu, tiwul instan merupakan salah satu oleh-oleh khas daerahnya, dan merupakan Kabupaten dengan produksi ubi kayu tertinggi di DI.Yogyakarta. Key informan sebagai entry point dalam penelitian ditentukan dengan metode purpossive sedangkan penentuan informan berikutnya dilakukan dengan metode snowball sampling. Key informan terdiri atas 7 agroindustri yang meliputi: Tiwul Manis Pak Lambang, Sediyo Mulyo, Putri 21, Manfaati, Sri Langgeng, Yu Tum, dan Ngudi Sari. Informan berikutnya terdiri atas 3 pengepul, 2 pedagang pasar, dan 15 petani.

Pengumpulan data dilakukan dengan observasi, wawancara, dan pencatatan. Analisis data dilakukan secara deskriptif kualitatif dengan pendekatan kerangka Food Supply Chain Network menurut Vorst, yang akan digunakan untuk mengambarkan manajemen rantai pasok ubi kayu di agroindustri tiwul instan. Kinerja rantai pasok dianalisis secara kuantitatif dengan pendekatan efisisensi pemasaran melalui perhitungan margin pemasaran dan farmer's share (Hidayat et al. 2017).

\section{HASIL DAN PEMBAHASAN}

\section{Mekanisme Manajemen Rantai Pasok Ubi Kayu}

1. Sasaran Rantai

a. Sasaran Pasar

Sebagian besar sasaran pasar produk yang dijual oleh pelaku rantai pasok ubi kayu adalah pasar domestik. Akan tetapi, terdapat sebagian pedagang yang menjual produk berupa gaplek ke pabrik untuk kemudian di ekspor ke luar negeri. Petani memilih menjual produknya kepada pengepul atau agroindustri tiwul instan daripada ke pedagang pasar karena harga yang ditetapkan lebih tinggi. Produk gaplek milik petani dihargai Rp 1.650,00/kg oleh pedagang, lebih rendah dibandingkan harga gaplek jika dijual ke pengepul yaitu Rp 1.750,00/kg

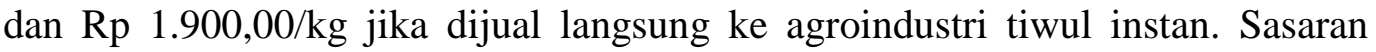
pasar agroindustri tiwul instan hanya ditujukan pada pasar domestik.

b. Sasaran Pengembangan

Sasaran pengembangan yang ingin dicapai dalam rantai pasok ini yaitu adanya peningkatan koordinasi dan kerjasama antar anggota rantai pasok agar keseluruhan anggota rantai menerima keuntungan yang lebih, peningkatan teknologi berupa mesin untuk "Nginteri" sehingga biaya tenaga kerja agroindustri dapat berkurang, serta adanya kontrak yang jelas antar anggota rantai pasok. Adanya kontrak ini diharapkan agar terdapat kepastian mengenai kualitas, kuantitas, kontinuitas, harga, waktu pembayaran serta kesepakatan lain yang dapat mengikat keseluruhan anggota rantai pasok.

2. Manajemen Rantai dan Jaringan 
a. Pemilihan Mitra

Penentuan mitra kerja untuk menjual hasil panen petani ubi kayu mempertimbangkan kesediaan mitra dalam mengambil hasil panen ke lahan secara langsung. Hal tersebut dilakukan guna mengurangi biaya dan kesulitan dalam transportasi, mengingat tidak semua petani memiliki alat transportasi untuk mendistribusikan hasil panennya. Pedagang tidak mempunyai kriteria khusus dalam menentukan mitra kerja baik mitra sebagai pemasok maupun sebagai pembeli.

Penentuan mitra pengepul khusus dan agroindustri tiwul instan mempertimbangkan kemampuan pemasok dalam memenuhi produk sesuai standar yang ditetapkan. Mitra yang dapat memasok produk kepada pengepul khusus dan agroindustri hanyalah pihak yang mampu memasok ubi kayu segar ataupun yang dapat memasok gaplek, chip gaplek atau tepung gaplek dengan kualitas super yaitu putih, bersih, kering sempurna dan tidak bau. Selain itu, petani mitra harus mampu melakukan proses produksi sesuai standard yang telah ditetapkan oleh pengepul khusus dan agroindustri tiwul instan. Pemilihan mitra pengepul khusus dan agroindustri tiwul instan tidak didasarkan kemampuan kuantitas pengiriman pemasok

b. Sistem Kontraktual

Terjadi kontrak informal secara lisan antar anggota rantai pasok ubi kayu di agroindustri tiwul instan baik dari pihak petani, pengepul maupun agroindustri berupa: kesepakatan harga dan kualitas produk yang harus dikirim ke pengepul. Kesepakatan antar anggota rantai mengenai kualitas yaitu produk gaplek, chip gaplek dan tepung gaplek harus putih, bersih, kering sempurna dan tidak berbau. Proses pengolahan ubi kayu menjadi gaplek, chip gaplek, dan tepung gaplek harus dilakukan sesuai standar yaitu dikupas hingga kulit dalam, dicuci hingga benar-benar bersih dan penjemuran dilakukan di tempat yang bersih atau tidak boleh dijemur diatas tanah. Apabila terjadi ketidaksesuaian kualitas produk bahan baku maka pihak agroindustri berhak mengembalikan produk kepada pemasok.

c. Sistem Transaksi

Sistem transaksi yang terjadi pada keseluruhan transaksi antar anggota rantai pasok ubi kayu di agroindustri tiwul instan sama yaitu dengan sistem "ada uang ada barang", dimana pembayaran dilakukan ketika barang sudah sampai ke tangan pembeli. Sistem pembayaran yang dilakukan secara langsung (cash) juga ditujukan agar setiap anggota rantai dapat langsung mendapatkan balas jasa atas aktivitas yang telah dilakukan.

d. Dukungan Pemerintah

Dukungan Pemerintah DI.Yogyakarta kepada petani dilakukan dengan memberikan bantuan dana yang disalurkan oleh Pemerintah Kabupaten Gunungkidul dalam bentuk pupuk yang dapat digunakan oleh 1000 hektar lahan dari keseluruhan lahan yang ada. Dukungan Pemerintah terhadap agroindustri tiwul instan berupa pemberian bantuan modal finansial dan peralatan, serta pelatihan proses produksi dan pengemasan.

e. Koordinasi dan Kolaborasi Rantai Pasok

Koordinasi dan kolaborasi dalam rantai pasok ditunjukkan dengan adanya information sharing antar anggota rantai pasok ubi kayu di agroindustri tiwul 
instan di Kabupaten Gunungkidul. Koordinasi dan kolaborasi juga dilakukan dalam pendistribusian produk yang memperhatikan kualitas, waktu pengiriman, dan alat transportasi sehingga dapat mencegah keterlambatan pengiriman. Pembayaran dilakukan tepat waktu dan adanya keinginan saling membantu dan bekerjasama antar anggota rantai.

\section{Struktur Rantai}

Struktur rantai pasok ubi kayu di agroindustri tiwul instan di Kabupaten Gunungkidul dapat dianalisis melalui anggota rantai yang membentuk struktur. Anggota rantai terdiri atas petani, pengepul, pedagang pasar dan pihak agroindustri tiwul instan. Strukur rantai pasok ubi kayu di agroindustri tiwul instan Kabupaten Gunungkidul dapat dilihat pada Gambar 1.

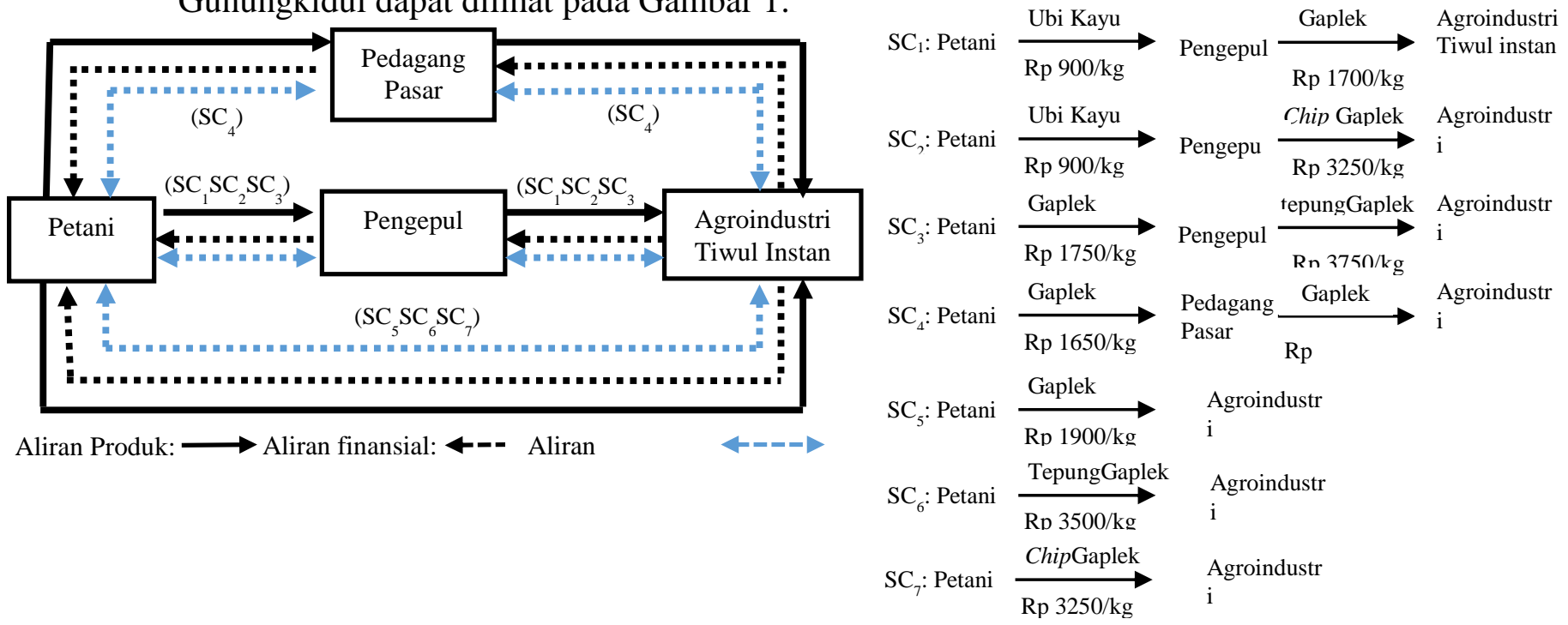

a. Petani Ubi Kayu

Gambar 1. Struktur Rantai Pasok

Rata-rata petani mengolah lahan dengan luas 1,09 hektar yang rata-rata menghasilkan 1,65 ton ubi tiap musim tanam. Sistem penanaman ubi kayu di Kabupaten Gunungkidul dilakukan secara tumpang sari. Aktivitas budidaya yang dilakukan oleh petani ubi kayu meliputi pengolahan lahan, penanaman, penyiangan, pemanenan dan pasca panen. Aktivitas pasca panen yang dilakukan yaitu pengolahan ubi kayu menjadi gaplek, chip gaplek atau tepung gaplek. Hasil penelitian menunjukkan bahwa $33,33 \%$ dari total petani yang diwawancarai menerapkan pola saluran SC7 yaitu Petani (Chip Gaplek) $\rightarrow$ Agroindustri Tiwul Instan. Petani memilih menjual langsung kepada agroindustri tiwul instan dalam bentuk chip gaplek karena memiliki nilai jual yang lebih tingi daripada dalam bentuk ubi kayu maupun gaplek.

b. Pengepul

Pengepul merupakan pihak yang mengumpulkan hasil panen ubi kayu dari petani untuk kemudian dijual kembali ke pihak lain. Aktivitas yang dilakukan oleh pengepul meliputi pengolahan pasca panen, penggilingan, penyimpanan, dan pengiriman. Aktivitas pasca panen meliputi proses pengupasan, pencucian, dan pengeringan untuk produk dari petani yang masih berupa ubi kayu segar.

c. Pedagang Pasar 
Pedagang pasar tidak berperan utama dalam rantai pasok ubi kayu di agroindustri tiwul instan karena pihak agroindustri sangat jarang membeli gaplek dari pihak pedagang. Produsen tiwul instan hanya akan membeli gaplek dari pedagang di pasar apabila terjadi kekurangan pasokan bahan baku dari pemasok utama. Hal tersebut karena kualitas gaplek yang dijual oleh pedagang di pasar tidak sesuai dengan kriteria gaplek yang dibutuhkan produsen tiwul instan.

d. Agroindustri Tiwul Instan

Agroindustri tiwul instan merupakan anggota rantai yang menjadi hilir atau ujung rantai pasokan ubi kayu sebagai bahan baku tiwul instan. Sebagai konsumen akhir bahan baku tiwul instan, pihak agroindustri berhak menentukan kualitas dan kuantitas produk yang dibutuhkan.

4. Sumberdaya Rantai

a. Sumberdaya Fisik

Sumberdaya fisik yang dimiliki petani ubi kayu yaitu lahan kering, cangkul, sabit, dan alat serut, serta akses jalan menuju lahan yang sudah dapat dijangkau alat transportasi. Sumberdaya fisik yang dimiliki pengepul meliputi alat serut, papan jemur (anjang), timbangan, ember untuk tampungan tepung gaplek, dan alat transportasi. Sumberdaya fisik yang dimiliki agroindustri yaitu papan jemur, timbangan, oven, mesin giling, ember tampungan, kompor, alat pengukus dan sealer. Semua sumberdaya fisik tersebut digunakan dalam proses produksi tiwul instan.

b. Sumberdaya Teknologi

Penggunaan teknologi oleh petani yaitu berupa taktor untuk mengolah tanah. Proses pengangkutan hasil panen dilakukan dengan kendaraan berupa motor, mobil, atau truk milik pembeli. Proses pengeringan ubi kayu oleh petani dan pengepul dilakukan dengan memanfaatkan panas matahari. Teknologi yang dimanfaatkan oleh agroindustri tiwul instan dalam proses produksi meliputi mesin giling, oven, sealer, alat pengukus dan kompor. Teknologi internet telah dimanfaatkan untuk proses pemasaran melalui sosial media instagram seperti yang dilakukan Tiwul Manis Pak Lambang dan UKM Ngudi Sari.

c. Sumbedaya Manusia

Sumberdaya manusia dalam rantai pasok terdiri atas petani, pengepul, pedagang pasar dan agroindustri tiwul instan. Rata-rata petani responden berumur 47 tahun yang masih merupakan usia produktif untuk bekerja. Petani ubi kayu rata-rata memiliki pendidikan terakhir SMP dan rata-rata telah bekerja sebagai petani selama 29 tahun. Sebagian dari petani yang dijadikan responden merupakan anggota kelompok tani sehingga mendapatkan pengetahuan mengenai budidaya dan pengolahan pasca panen yang termasuk pula pengetahuan mengenai proses pengolahan ubi kayu menjadi chip gaplek.

Petani dan pengepul telah mengupayakan agar tetap dapat memberikan kepuasan bagi agroindustri tiwul instan dengan memasok bahan baku berkualitas baik yaitu putih, bersih, kering sempurna dan tidak bau. Pelatihan dan pengembangan sumberdaya manusia beberapa kali telah dilaksanakan melalui kerjasama dengan LIPI, Dinas Pertanian serta BIMTEK. Pelatihan yang diberikan yaitu mengenai pengemasan yang baik serta proses produksi sesuai SOP.

d. Sumberdaya Modal 
Modal usaha yang dimiliki petani dan pengepul berasal dari modal sendiri. Modal usaha yang dimiliki oleh agroindustri tiwul instan berasal dari modal sendiri, pinjaman bank, bantuan dari pemerintah, lembaga keuangan islam atau koperasi syariah, dan PNPM Mandiri. Bantuan modal dari pemerintah berupa bantuan finansial dan peralatan

5. Proses Bisnis Rantai

a. Hubungan Proses Bisnis

Terdapat dua pandangan dalam menentukan proses bisnis yaitu pandangan cycle view dan push or pull view (Chopra dan Meindl 2004). Siklus procurenment dilakukan oleh pengepul dan pedagang sebagai distributor yang membeli bahan baku berupa gaplek atau ubi kayu dari petani sebagai supplier. Siklus manufacturing dilakukan oleh pihak pengepul karena mereka mengolah ubi kayu menjadi gaplek atau tepung gaplek. Siklus replenishment dilakukan oleh pihak pengepul karena pada masa tertentu terutama bukan masa panen, pengepul akan meminta pasokan lebih dari petani sebagai upaya untuk menjaga stok sehingga tetap dapat menjaga kontinuitas pasokan ke agroindustri tiwul instan sebagai konsumen akhir dalam penelitian ini. Siklus costumer order dilakukan oleh pihak agroindustri tiwul instan sebagai konsumen akhir dalam penelitian ini. Siklus costumer order ini dilakukan dengan memesan gaplek, chip gaplek atau tepung gaplek kepada pengepul, pedagang, maupun langsung kepada petani.

Agroindustri tiwul instan sebagai konsumen akhir dalam rantai pasok ubi kayu melakukan pemesanan atau pembelian produk kepada pengepul dan pedagang. Pemesanan yang terjadi merupakan siklus costumer order. Proses push terjadi ditunjukkan dengan berlangsungnya proses produksi tanpa menunggu kepastian permintaan dari konsumen. Baik petani maupun pengepul terus melakukan produksi ubi kayu, gaplek, chip gaplek maupun tepung gaplek secara terus-menerus tanpa menunggu adanya permintaan dari konsumen yaitu agroindustri tiwul instan. Proses ini dilakukan karena ubi kayu hanya dipanen selama empat bulan dalam setahun.

b. Pola Distribusi

Pola distribusi atau aliran produk, finansial, dan informasi dalam rantai pasok ubi kayu di agroindustri tiwul instan Kabupaten Gunungkidul dapat dilihat pada Gambar 1. Agroindustri tiwul instan di Kabupaten Gunungkidul menerapkan pola saluran distribusi yang berbeda-beda. Saluran $\mathrm{SC}_{1}, \mathrm{SC}_{2}, \mathrm{SC}_{3}$, dan $\mathrm{SC}_{4}$ masing-masing diterapkan oleh $14,29 \%$ dari total agroindustri yang diteliti. Saluran $\mathrm{SC}_{5}$ dan $\mathrm{SC}_{6}$ masing-masing diterapkan oleh 42,89\% agroindustri sedangkan 28,57\% agroindustri menerapkan $\mathrm{SC}_{7}$.

1) Aliran Produk

Aliran produk dari hulu ke hilir pada masing-masing saluran rantai pasok ubi kayu di agroindustri tiwul instan dapat dilihat pada Tabel 2.

Tabel 2. Aliran Produk setiap Saluran Rantai Pasok Ubi Kayu di Agroindustri Tiwul Instan Kabupaten Gunungkidul

\begin{tabular}{cllc}
\hline \multirow{2}{*}{ SALURAN } & \multicolumn{3}{c}{ Produk } \\
\cline { 2 - 4 } & \multicolumn{1}{c}{ Petani } & \multicolumn{1}{c}{ Pengepul } & Pedagang \\
\hline $\mathrm{SC}_{1}$ & Ubi Kayu & Gaplek & - \\
$\mathrm{SC}_{2}$ & Ubi Kayu & Chip Gaplek & -
\end{tabular}




\begin{tabular}{llcr}
$\mathrm{SC}_{3}$ & Gaplek & Tepung Gaplek & - \\
$\mathrm{SC}_{4}$ & Gaplek & - & Gaplek \\
$\mathrm{SC}_{5}$ & Gaplek & - & - \\
$\mathrm{SC}_{6}$ & Tepung Gaplek & - & - \\
$\mathrm{SC}_{7}$ & Chip Gaplek & - & - \\
\hline
\end{tabular}

\section{Sumber: Analisis Data Primer (2018)}

2) Aliran Finansial

Aliran finansial dari hilir ke hulu pada masing-masing saluran rantai pasok ubi kayu di agroindustri tiwul instan Kabupaten Gunungkidul dapat dilihat pada Tabel 3.

Tabel 3. Aliran Finansial Rantai Pasok Ubi Kayu di Agroindustri Tiwul Instan Kabupaten Gunungkidul

\begin{tabular}{llrlcccc}
\hline \multirow{2}{*}{$\mathrm{SC}$} & \multicolumn{2}{c}{ Petani } & \multicolumn{2}{c}{ Pengepul } & \multicolumn{2}{c}{ Pedagang } & Sistem \\
\cline { 2 - 6 } & Bentuk & $\mathrm{Rp} / \mathrm{kg}$ & Bentuk & $\mathrm{Rp} / \mathrm{kg}$ & Bentuk & $\mathrm{Rp} / \mathrm{kg}$ & Transaksi \\
\cline { 2 - 6 } $\mathrm{SC}_{1}$ & Ubi & 900 & Gaplek & 1700 & - & - & Cash \\
$\mathrm{SC}_{2}$ & Ubi & 900 & Chip & 3250 & - & - & Cash \\
$\mathrm{SC}_{3}$ & Gaplek & 1750 & Tepung & 3750 & - & - & Cash \\
$\mathrm{SC}_{4}$ & Gaplek & 1650 & - & - & Gaplek & 1900 & Cash \\
$\mathrm{SC}_{5}$ & Gaplek & 1900 & - & - & - & - & Cash \\
$\mathrm{SC}_{6}$ & Tepung & 3500 & - & - & - & - & Cash \\
$\mathrm{SC}_{7}$ & chip & 3250 & - & - & - & - & Cash \\
\hline
\end{tabular}

\section{Sumber: Analisis Data Primer (2018)}

3) Aliran Informasi

Aliran informasi yang terjadi yaitu mengenai waktu panen, kualitas dan karakteristik produk yang diinginkan, proses produksi yang sesuai, serta informasi mengenai harga pada masing-masing tingkat rantai pasok. Gambaran mengenai aliran informasi dalam rantai pasok dapat dilihat pada Gambar 2, dimana arah panah menunjukkan informasi yang berjalan secara dua arah yaitu dari hulu ke hilir dan dari hilir ke hulu.

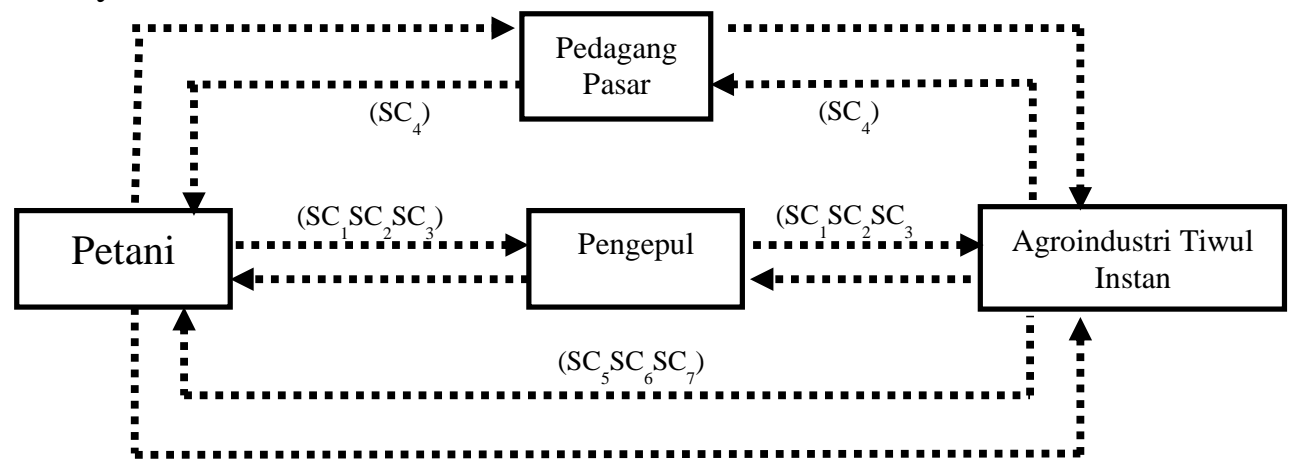

Gambar 2. Aliran Informasi Rantai Pasok (Analisis Data Primer 2018)

Pada saluran $\mathrm{SC}_{1}, \mathrm{SC}_{2}$, dan $\mathrm{SC}_{3}$ aliran informasi berjalan dari petani ke pengepul kemudian diteruskan ke agroindustri tiwul instan, dan berjalan sebaliknya. Pada saluran $\mathrm{SC}_{4}$, informasi mengalir dari petani ke pedagang pasar kemudian dilanjutkan kepada agroindustri tiwul instan, dan berjalan 
sebaliknya. Sedangkan pada saluran $\mathrm{SC}_{5}, \mathrm{SC}_{6}$, dan $\mathrm{SC}_{7}$ informasi mengalir dari petani langsung kepada agroindustri tiwul instan dan berjalan sebaliknya.

c. Resiko dan Trust Building

Resiko yang dihadapi oleh petani ubi kayu seringkali berkaitan dengan sifat ketidakpastian produksi pertanian yaitu keterlambatan dan gagal panen akibat cuaca yang tidak sesuai. Bagi sebagian petani yang menjual ubi kayu dalam bentuk gaplek, resiko yang mungkin dialami yaitu gaplek berkualitas rendah dan tidak kering sempurna akibat cuaca yang kurang mendukung. Keberadaan petani yang berperan sebagai price taker menjadikan petani beresiko memperoleh pendapatan yang kurang setimpal.

Bagi pengepul yang membeli gaplek dari petani, resiko yang mungkin dialami adalah rendahnya kualitas gaplek seperti warna tidak putih dan tidak kering sempurna. Kualitas yang kurang baik tersebut tidak sesuai dengan yang diinginkan oleh pihak agroindustri tiwul instan sehingga memungkinkan terjadinya penolakan dan pengembalian produk. Resiko yang mungkin dihadapi agroindustri yaitu keterlambatan pengiriman pasokan, ketidaksesuaian kualitas, maupun rusaknya gaplek atau tepung gaplek akibat proses penyimpanan.

Rasa kepercayaan dibangun dengan cara memberikan pelayanan yang terbaik dan memuaskan pihak lain. Kepercayaan dibangun dengan menciptakan keterbukaan informasi dan melakukan pembayaran tepat waktu. Rasa kepercayaan juga terjalin karena sebagian pelaku rantai pasokan sudah saling mengenal satu sama lain.

\section{Model Manajemen Rantai Pasok Ubi Kayu}

Model sistem manajemen rantai pasok ubi kayu di agroindustri tiwul instan terdiri atas petani sebagai penyedia input, pengepul dan pedagang sebagai penyedia produk dan pengolah produk menjadi bahan baku, serta agroindustri tiwul instan sebagai pengolah bahan baku dan penghasil produk baru (output). Model sistem yang terdiri atas peranan pelaku rantai pasok mulai dari petani sampai agroindustri tiwul instan dapat dilihat pada Gambar 3.

\begin{tabular}{|c|c|c|}
\hline $\begin{array}{l}\quad \text { Petani Ubi Kayu } \\
\text { Input: lahan, bibit, pupuk } \\
\text { Process: Pengolahan } \\
\text { tanah, penanaman, } \\
\text { pemeliharaan, panen, } \\
\text { Pengupasan, } \\
\text { Pemotongan, } \\
\text { Penjemuran, Penjualan, } \\
\text { Output: Ubi kayu, } \\
\text { Gaplek, chip gaplek, } \\
\text { tepung gaplek }\end{array}$ & $\begin{array}{l}\text { Pengepul } \\
\text { Input: ubi kayu, gaplek } \\
\text { Process: } \\
\text { Pembelian, Pemilahan, Pengupasan, } \\
\text { Penjemuran, Penggilingan, Penjualan } \\
\text { Output: gaplek, chip gaplek, tepung gaplek }\end{array}$ & $\begin{array}{l}\quad \begin{array}{l}\text { Agroindustri } \\
\text { (Tiwul Instan) }\end{array} \\
\text { Input: tepung } \\
\text { gaplek } \\
\text { Process: Pembelian } \\
\text { bahan baku, } \\
\text { Pengolahan produk } \\
\text { baru, Penjualan } \\
\text { produk baru (tiwul } \\
\text { instan } \\
\text { Output: tiwul instan }\end{array}$ \\
\hline
\end{tabular}

Gambar 3. Model Sistem Manajemen Rantai Pasok 


\section{Kinerja Rantai Pasok}

Berdasarkan Gambar 2, diketahui bahwa terdapat tujuh pola saluran dengan produk yang berbeda-beda. Penelitian ini bertujuan untuk mengkaji kinerja rantai pasok ubi kayu melalui perhitungan margin pemasaran dan farmer's share. Oleh sebab itu, sebelum dilakukan perhitungan margin dan farmer's share pada masing-masing saluran, harga produk dalam bentuk gaplek, chip gaplek dan tepung gaplek terlebih dahulu di konversikan ke dalam bentuk ubi kayu. Konversi produk dilakukan dengan ketentuan sebagai berikut, dimana: $1 \mathrm{~kg}$ ubi kayu setara dengan $0,3 \mathrm{~kg}$ gaplek, $1 \mathrm{~kg}$ ubi kayu setara dengan 0,4 kg chip gaplek, $1 \mathrm{~kg}$ ubi kayu setara dengan 0,35 kg tepung gaplek, dan $1 \mathrm{~kg}$ gaplek setara dengan $0,875 \mathrm{~kg}$ tepung gaplek.

1. Margin Pemasaran

Marjin pemasaran merupakan perbedaan harga yang diterima oleh petani dengan harga yang dibayarkan oleh konsumen (Jumiati et.al 2013). Margin pemasaran pada masing-masing saluran rantai pasok dapat dilihat pada Tabel 4.

Tabel 4. Margin Pemasaran setiap Saluran Rantai Pasok Ubi Kayu di Agroindustri Tiwul Instan Kabupaten Gunungkidul

\begin{tabular}{|c|c|c|c|c|c|c|c|}
\hline \multirow[t]{2}{*}{$\begin{array}{c}\text { Anggota } \\
\text { Rantai }\end{array}$} & $\mathbf{S C}_{1}$ & $\mathbf{S C}_{2}$ & $\mathbf{S C}_{3}$ & $\begin{array}{c}\text { SC } \\
4 \\
\end{array}$ & $\mathrm{SC}_{5}$ & $\mathrm{SC}_{6}$ & $\mathbf{S C}_{7}$ \\
\hline & \multicolumn{7}{|c|}{$(\mathbf{R p} / \mathrm{Kg})$} \\
\hline \multicolumn{8}{|l|}{ Petani } \\
\hline Harga Jual & 900 & 900 & 525 & 495 & 570 & 1225 & 1300 \\
\hline \multicolumn{8}{|l|}{ Pengepul } \\
\hline Harga Beli & 900 & 900 & 525 & 495 & 570 & 1225 & 1300 \\
\hline Harga Jual & 510 & 1300 & 1312,5 & - & - & - & - \\
\hline Biaya & 45 & 60 & 52,5 & - & - & - & - \\
\hline \multicolumn{8}{|l|}{ Transportasi } \\
\hline Biaya Pengolahan & 75 & 240 & 210 & - & - & - & - \\
\hline Biaya & - & - & 140 & - & - & - & - \\
\hline \multicolumn{8}{|l|}{ Penggilingan } \\
\hline Total Biaya & 120 & 300 & 402,5 & - & - & - & - \\
\hline Keuntungan & -510 & 100 & 385 & - & - & - & - \\
\hline Margin & 390 & 400 & 787,5 & - & - & - & - \\
\hline \multicolumn{8}{|l|}{ Pedagang } \\
\hline Harga Beli & - & - & - & 495 & - & - & - \\
\hline Harga Jual & - & - & - & 570 & - & - & - \\
\hline Biaya & - & - & - & 15 & - & - & - \\
\hline \multicolumn{8}{|l|}{ Transportasi } \\
\hline Biaya Pengolahan & - & - & - & - & - & - & - \\
\hline Biaya & - & - & - & - & - & - & - \\
\hline \multicolumn{8}{|l|}{ Penggilingan } \\
\hline Total Biaya & - & - & - & 15 & - & - & - \\
\hline Keuntungan & - & - & - & 60 & - & - & - \\
\hline Margin & - & - & - & 75 & - & - & - \\
\hline \multicolumn{8}{|l|}{ Agroindustri } \\
\hline Harga Beli & 510 & 1300 & 1312,5 & 570 & 570 & 1225 & 1300 \\
\hline Total Margin & 390 & 400 & 787,5 & 75 & $\mathbf{0}$ & $\mathbf{0}$ & $\mathbf{0}$ \\
\hline Biaya/keuntungan & $-4,25$ & $\mathbf{0 , 3 3}$ & 0,95 & 4 & & & \\
\hline
\end{tabular}

Sumber: Analisis Data Primer (2018)

Berdasarkan Tabel 4, diketahui bahwa nilai margin terendah terdapat pada $\mathrm{SC}_{5}$, $\mathrm{SC}_{6}$, dan $\mathrm{SC}_{7}$. Hal ini disebabkan pihak petani menjual produknya secara langsung kepada pihak agroindustri tiwul instan tanpa perantara siapapun. Margin terbesar 
terdapat pada $\mathrm{SC}_{3}$ yaitu $\mathrm{Rp}$. 787,5/kg dimana produk mengalir dari petani pengepul - agroindustri tiwul instan.

Saluran 3 memiliki margin yang terbesar karena pada saluran ini petani menjual produknya dalam bentuk gaplek. Untuk menghasilkan satu kilogram gaplek, petani harus menyediakan ubi kayu sebanyak 3,3 kilogram. Harga beli ubi kayu ditingkat pengepul akan cenderung lebih rendah karena berdasarkan konversi tersebut pengepul membeli ubi kayu dalam jumlah yang lebih banyak. Pengepul pada saluran $\mathrm{SC}_{3}$ mengeluarkan biaya untuk melakukan pengolahan gaplek menjadi tepung gaplek serta mendistribusikannya kepada agroindustri tiwul instan. Pada saluran $\mathrm{SC}_{1}$ harga ubi kayu di tingkat pengepul sebesar Rp. 510,00/kg lebih rendah daripada harga di tingkat petani yaitu Rp.900,00. Hal tersebut menunjukkan bahwa aktivitas nilai tambah yang dilakukan tidak begitu menguntungkan.

2. Farmer's Share

Nilai farmer's share pada setiap saluran rantai pasok dapat dilihat pada Tabel 5.

Tabel 5. Farmer's Share Setiap Saluran Rantai Pasok Ubi Kayu di Agroindustri Tiwul Instan

\begin{tabular}{cccc}
\hline Jenis & Harga Jual Petani & Harga Jual Akhir & Farmer's Share \\
\cline { 2 - 4 } Saluran & $(\mathbf{R p} / \mathbf{k g})$ & $\mathbf{( R p / k g )}$ & $(\mathbf{\%})$ \\
\hline SC 1 & 900 & 510 & 176,47 \\
SC 2 & 900 & 1300 & 69,23 \\
SC 3 & 525 & 1312,5 & 40,00 \\
SC 4 & 495 & 570 & 86,84 \\
SC 5 & 570 & 570 & 100,00 \\
SC 6 & 1225 & 1225 & 100,00 \\
SC 7 & 1300 & 1300 & 100,00 \\
\hline
\end{tabular}

\section{Sumber: Analisis Data Primer (2018)}

Berdasarkan Tabel 5, diketahui bawa saluran $\mathrm{SC}_{1}$ memiliki nilai farmer's share paling tinggi yaitu sebesar $176,47 \%$. Pada saluran ini agroindustri tiwul instan membeli produk dalam bentuk gaplek yang apabila setiap kilogramnya dikonversikan akan setara dengan 3,3 kilogram ubi kayu. Hal tersebut menunjukkan bahwa agroindustri secara tidak langsung membeli ubi kayu dengan kuantitas yang lebih banyak sehingga dapat menurunkan harga ubi kayu per kilogram pada tingkat lembaga pemasaran sebelumnya yaitu pengepul. Harga jual di tingkat pengepul yang lebih rendah dibandingkan harga di tingkat petani menjadikan farmer's share pada saluran $\mathrm{SC}_{1}$ bernilai tinggi.

Aktivitas nilai tambah yang dilakukan petani dalam mengolah ubi kayu menjadi gaplek (SC5), tepung gaplek (SC6), dan chip gaplek (SC7), menjadikan harga jual di tingkat petani meningkat sehingga nilai farmer's share pada ketiga saluran tersebut tinggi. Saluran ketiga (SC3) memiliki nilai farmer's share yang rendah karena pihak pengepul sebagai perantara melakukan aktivitas pengolahan sehingga memunculkan biaya tambahan yang dapat meningkatkan nilai jualnya. Kohls dan Uhl (2002) menyatakan bahwa apabila aktivitas nilai tambah utilitas pada suatu komoditas banyak dilakukan petani maka nilai farmer's share yang diperoleh lebih tinggi. Namun apabila aktivitas nilai tambah utilitas komoditas tersebut banyak dilakukan oleh lembaga-lembaga pemasaran lain, pada umumnya akan menghasilkan nilai farmer's share yang lebih rendah. 
Hasil penelitian menunjukkan bahwa saluran SC5, SC6, dan SC7 memiliki margin pemasaran Rp.0,00/kg dan farmer's share sebesar $100 \%$. Hal ini belum menunjukkan bahwa saluran SC5, SC6, dan SC7 merupakan saluran yang paling efisien dikarenakan produk disalurkan dari petani ubi kayu langsung kepada agroindustri tiwul instan sehingga tidak ada distribusi keuntungan dengan lemabaga pemasaran. Saluran SC1 memiliki farmer's share yang tinggi akibat harga jual ubi kayu pada tingkat pengepul justu semakin rendah yaitu Rp. 510,00/kg sedangkan harga ubi kayu di tingkat petani adalah Rp. 900,00/kg sehingga tidak memberikan keuntungan bagi pengepul sebagai lembaga pemasaran.

Berdasarkan tabel 4, dapat diketahui biaya dan keuntungan yang diperoleh masing-masing pelaku rantai dalam setiap saluran. Saluran SC4 memiliki rasio keuntungan dan biaya yang paling besar dibandingkan dengan saluran lainnya. Saluran SC4 juga memiliki nilai margin pemasaran yang rendah dan farmer's share yang tinggi dibanding saluran lain. Hal tersebut menunjukkan bahwa saluran SC4 merupakan saluran yang efisien.

Hasil penelitian menunjukkan bahwa petani lebih banyak memilih pola saluran SC7 yaitu Petani (chip gaplek) $\rightarrow$ agroindustri tiwul instan sedangkan pihak agroindustri lebih banyak yang menerapkan pola saluran SC5 dan SC6 yaitu Petani (gaplek) $\rightarrow$ agroindustri tiwul instan dan Petani (tepung gaplek) $\rightarrow$ agroindustri tiwul instan. Berdasarkan analisis efisiensi pemasaran, saluran yang efisien adalah saluran SC4, akan tetapi pada kenyataannya saluran ini justru hanya diterapkan oleh sebagian pelaku rantai akibat kualitas produk yang berjalan tidak sesuai dengan kriteria produk yang dibutuhkan. Saluran SC4 hanya diterapkan oleh $13,33 \%$ dari total petani responden dan 14,29\% dari agroindustri tiwul instan. Hal tersebut menunjukkan bahwa saluran yang kebanyakan diterapkan oleh pelaku rantai merupakan saluran yang kurang efisien.

\section{KESIMPULAN}

Manajemen rantai pasok ubi kayu di Agroindustri tiwul instan meliputi kesepakatan kontraktual yang berupa kontrak lisan antar anggota, sistem transaksi dilakukan secara tunai, dan pemilihan mitra didasarkan pada kesediaan untuk mengambil hasil panen dan melakukan proses produksi sesuai standar yang ditetapkan. Dukungan pemerintah berupa bantuan modal, peralatan, serta pelatihan pengembangan sumberdaya manusia. Koordinasi dan kolaborasi dalam rantai pasok diciptakan dengan adanya information sharing, penyediaan transportasi untuk distribusi produk, pembayaran tepat waktu dan keinginan saling membantu dan bekerjasama antar anggota rantai. Model manajemen rantai pasok ubi kayu di agroindustri tiwul instan Kabupaten Gunungkidul terdiri atas petani, pengepul, pedagang pasar, dan agroindustri tiwul instan sebagai pelaku rantai yang masing-masing melakukan aktivitas berbeda bergantung pada input yang dimiliki dan output yang dihasilkan. Saluran yang paling efisien adalah $\mathrm{SC}_{4}$ (Petani (gaplek) $\rightarrow$ pedagang pasar (gaplek) $\rightarrow$ agroindustri tiwul instan). Saluran tersebut dinilai efisien karena memiliki nilai margin pemasaran relatif rendah, farmer's share yang relatif tinggi serta rasio keuntungan dan biaya yang lebih tinggi dibandingkan saluran lain. 


\section{DAFTAR PUSTAKA}

Atmasari, N. 2015. Libur Akhir Tahun Oleh-oleh Tiwul "Yu Tum" Laris Manis. http://www.jatengpos.com. Diakses pada 6 Desember 2017.

Chopra dan Meindl. 2004. Supply Chain Management: Strategy, Planning \& Operations. Pearson Prentice Hall, New Jersey

Disperindag Gunungkidul. 2015. IKM Kabupaten Gunungkidul. Gunungkidul: Dinas Perindustrian dan Perdagangan Kabupaten Gunungkidul

Distan DIY. 2017. Statistik Tanaman Pangan. diakses pada 26 Oktober 2017. http://distan.jogjaprov.go.id

Handayani, SM dan Ivana N. 2011. Analisis Pemasaran Susu Segar di Kabupaten Klaten. Sains Peternakan Volume IX No 1.

Hidayat, Sri, dan Jaka. 2017. Analisis Rantai Pasok Jagung (Studi Kasus pada Rantai Pasok Jagung Jibrida (Zea mays) di Kelurahan Cicurug Kecamatan Majalengka Kabupaten Majalengka). Jurnal Ilmu Pertanian dan Peternakan Volume 5 No 1

Indrajit, R.E dan Djokopranoto. 2002. Konsep Managemen Supply Chain. Grasindo, Jakarta

Jumiati, Dwidjono, Slamet dan Masyhuri. 2013. Analisis Saluran Pemasaran dan Marjin Pemasaran Kelapa Dalam di Daerah Perbatasan Kalimantan Timur. Jurnal AGRIFOR Volume XII No 1

Kamilah, S dan Lucia T P. 2015. Pengaruh Substitusi Tepung Twiul Tawar Instan terhadap SIfat Organoleptik Chiffon Cake. E-Journal Boga, Volume 04 Edisi Yudisium Periode Oktober 2015, halaman 49-56

Kohls, R.L. dan Uhl, JN. 2002. Marketing of Agricultural Products 9th Editions. Macmillan Company, New York

Vorst, V. 2006. Performance Measurenment in Agrifood Supply Chain Network: An Overview In: Quantifying the Agrifood Supply Chain. Dodrecht: Spingerl Kluwer. (Wageningen UR Frontis Series 15) 